This PDF is a selection from a published volume from the National Bureau of Economic Research

Volume Title: Trade in Services in the Asia Pacific Region, NBER East Asia Seminar on Economics (EASE), Volume 11

Volume Author/Editor: Takatoshi Ito and Anne O. Krueger, editors

Volume Publisher: University of Chicago Press

Volume ISBN: 0-226-38677-5

Volume URL: http://www.nber.org/books/ito_03-1

Conference Date: June 22-24, 2000

Publication Date: January 2003

Title: A Study of Competitiveness of International Tourism in the Southeast Asian Region

Author: Kuo-Liang Wang, Chung-Shu Wu

URL: http://www.nber.org/chapters/c10163 


\title{
A Study of Competitiveness of International Tourism in the Southeast Asian Region
}

\author{
Kuo-Liang Wang and Chung-Shu Wu
}

\subsection{Introduction}

Along with the continuing growth of national income in most countries, the substantial decline in the real costs of transportation, the liberalization of cross-border movements, and the increasing propensity to travel abroad, the number of total international visitors in the world as a whole kept growing during the period of 1973 to 1994 (figure 10.1). Therefore, most economies in the Southeast Asian region had devoted themselves to international tourism. As a result, total international arrivals to Southeast Asia and the region's share of the total world tourists had been steadily growing (figures 10.2 and 10.3), and all economies in the region had a growing or fairly stable share of the world market (figure 10.4). However, compared with their neighbors in the region, Taiwan, the Philippines, and Singapore had been continuously losing ground in the market for international tourism since the mid-1970s, the end of 1970s, and the beginning of 1980s, respectively; Indonesia had been continuously gaining ground since the mid-1980s; Hong Kong, Malaysia, and Thailand had experienced fluctuations, but still followed a rising trend. Thus, although some economies had been continuously losing ground, other economies had been continuously gaining ground or had experienced fluctuations in international tourism (figure 10.5).

The purpose of this paper is to investigate and identify the factors respon-

The authors are grateful to Anne O. Krueger, Takatoshi Ito, two anonymous referees, and seminar participants, particularly discussants Keiko Ito and Mahani Zainal-Abidin, for constructive comments and useful suggestions. The authors would also like to thank the Tourism Bureau of Taiwan for its kind help with data collection. All remaining errors are the authors'. 


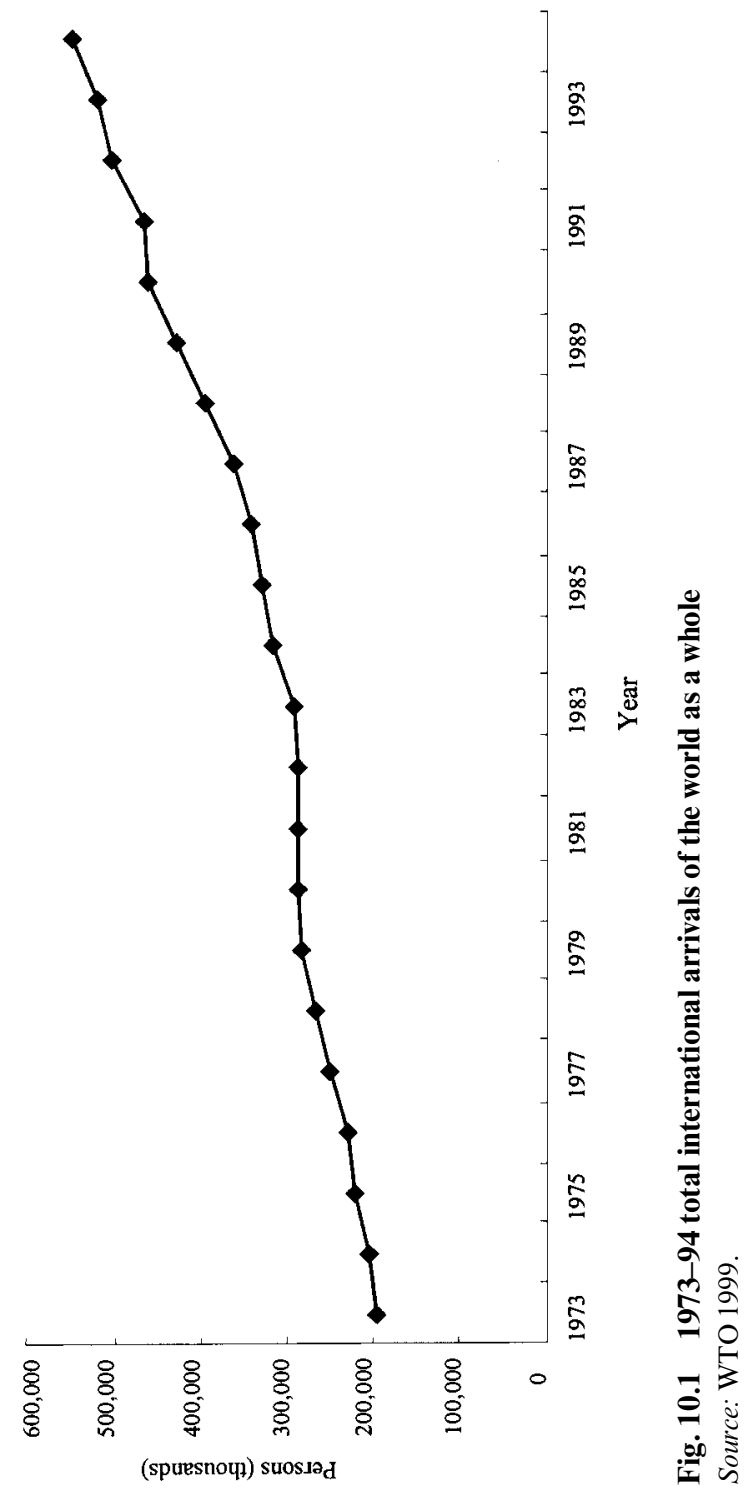




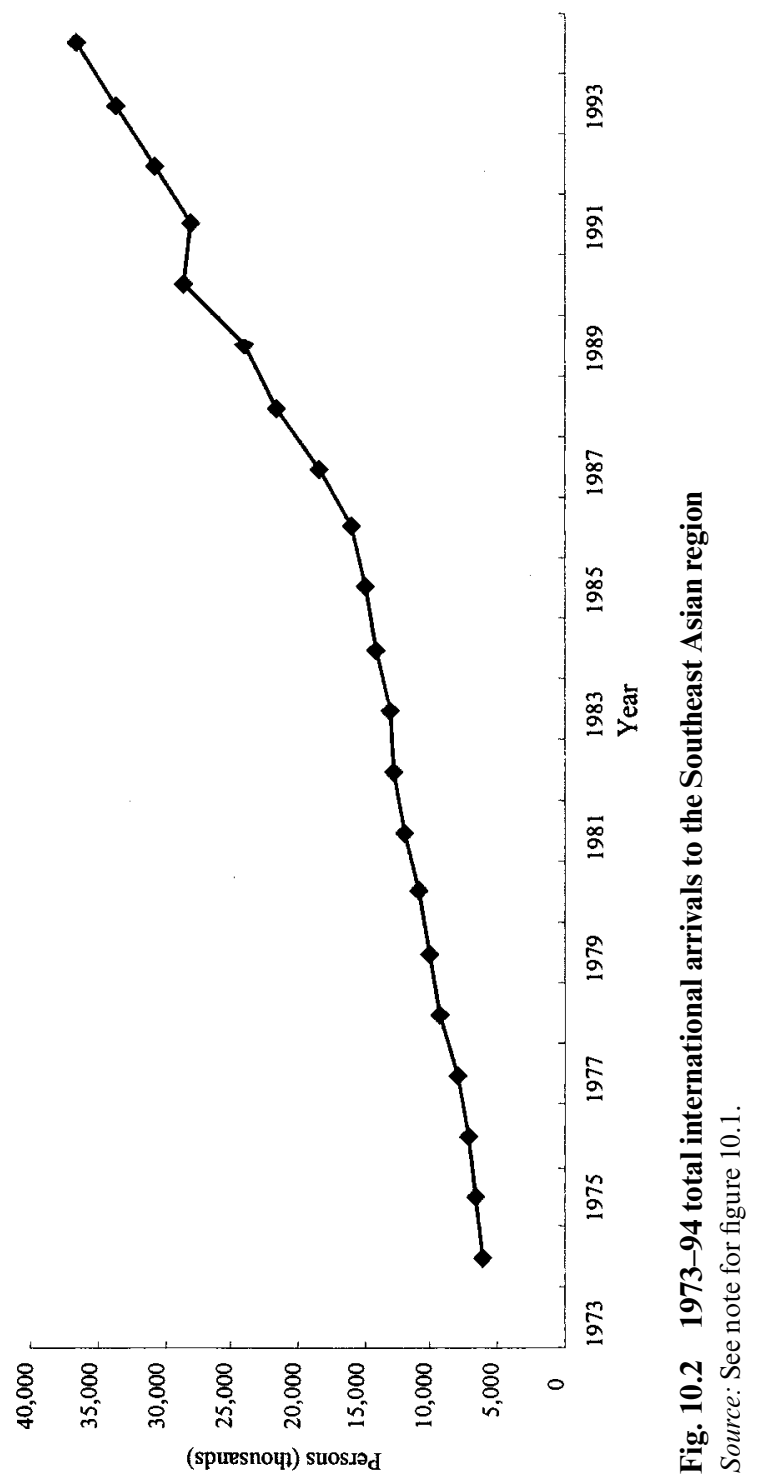




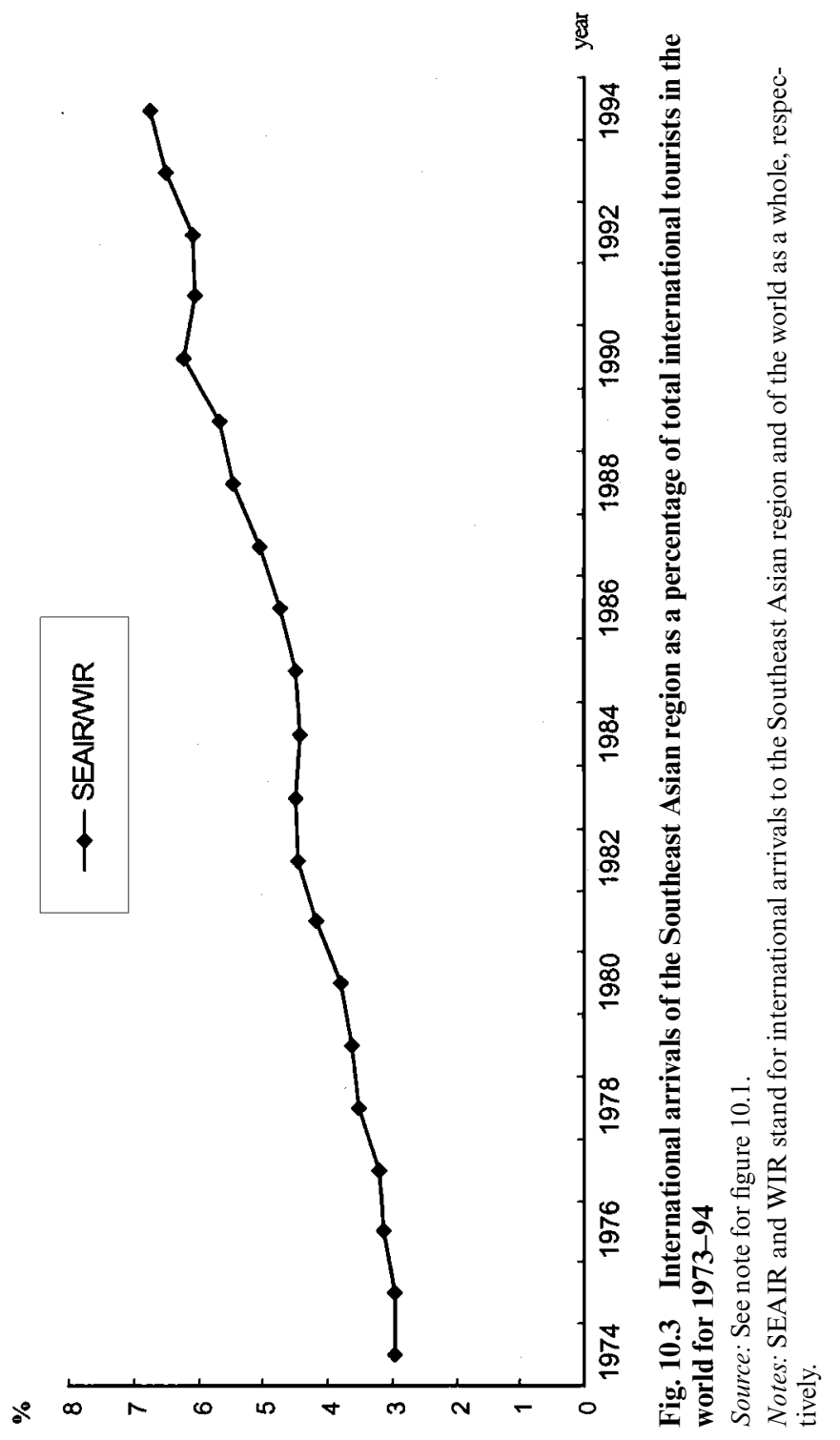




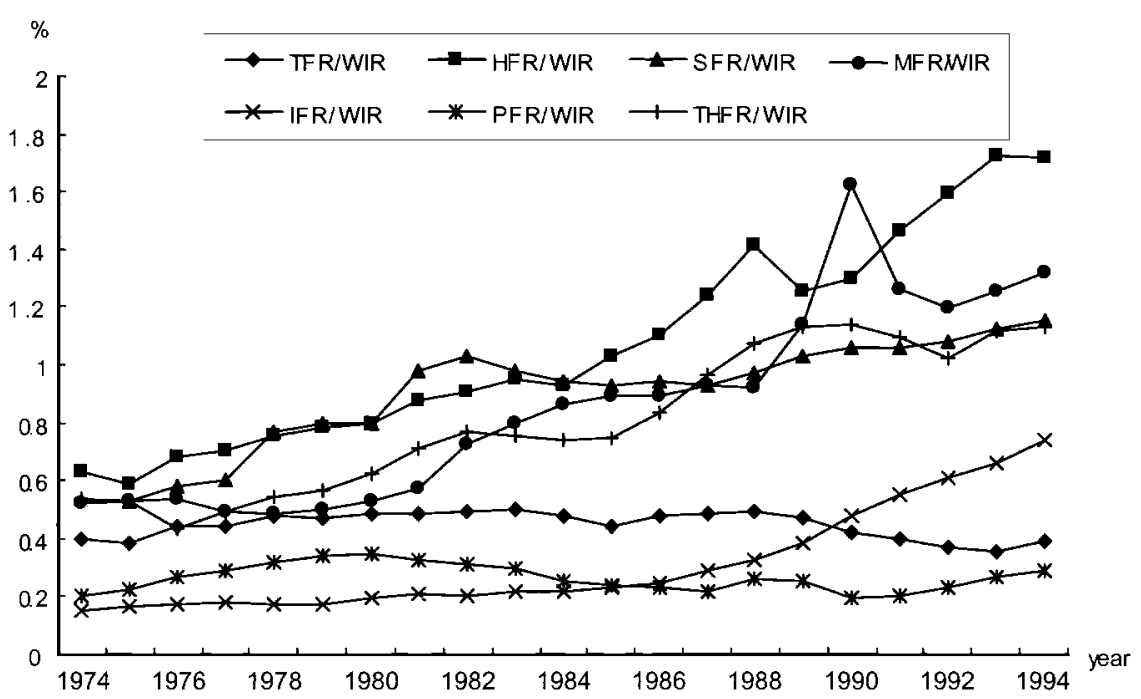

Fig. 10.4 Foreign arrivals of each economy as a percentage of total international tourists in the world for 1973-94

Source: See note for figure 10.1.

Notes: TFR, HRF, SFR, MFR, IFR, PFR, and THFR stand for foreign arrivals to Taiwan, Hong Kong, Singapore, Malaysia, Indonesia, the Philippines, and Thailand, respectively.

sible for each economy's changing competitiveness in international tourism among a group of seven Southeast Asian economies (Taiwan, Hong Kong, and the Association of Southeast Asian Nations (ASEAN) Five, namely, Singapore, Malaysia, Indonesia, the Philippines, and Thailand. ${ }^{1}$ The rest of the paper is organized as follows. Section 10.2 sets up a theoretical model, on which our empirical study is based. Section 10.3 discusses the nature and problems of the sample, variables, and data used in the empirical study. Section 10.4 carries out statistical analyses and reports the preliminary findings. The final section concludes the paper.

\subsection{Model Building}

Consumer demand theory has been the major framework used to study the determinants of demand for tourism services. Empirically, there are two main approaches to modeling the demand for tourism: the single-equation approach and the simultaneous-equations approach. The single-equation

1. These economies are chosen because of their geographical proximity, their similarity in development strategy, and the fact that they have been close rivals in so many product lines on the world markets in recent years. 


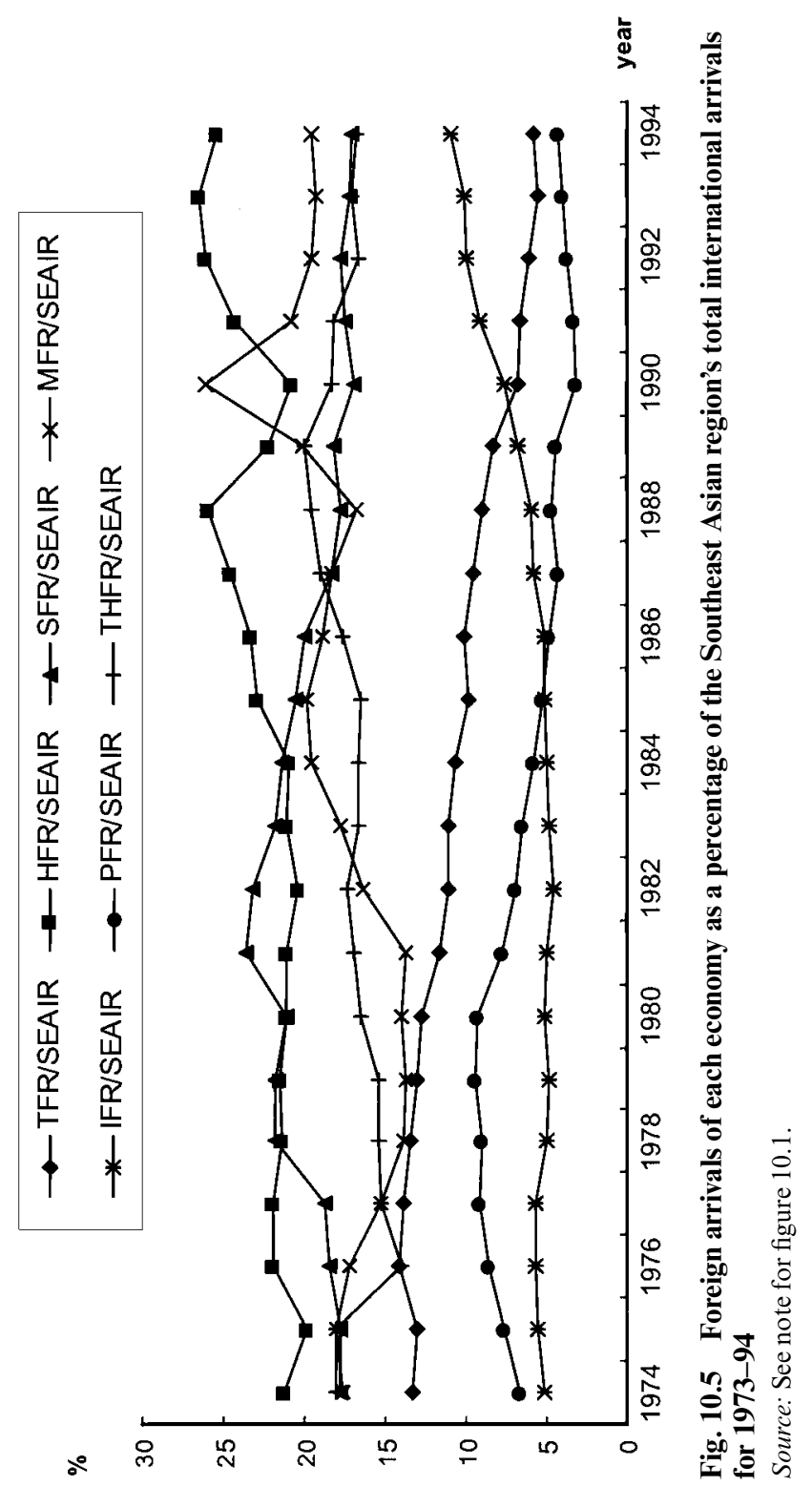


approach postulates that tourism demand, as measured by tourist expenditures (receipts) or the number of tourist arrivals, depends upon income, relative prices, or exchange rates, and transport costs, as well as other factors like marketing expenditures, political disruptions, or major sporting events. Although studies applying this approach have provided useful insights, the degree of detail that can be included in a single-equation estimation is still limited (Eadington and Redman, 1991). As a consequence, some researchers have shifted to the simultaneous-equations models, most of which are based on Deaton and Muellbauer's (1980) almost ideal demand system (AIDS). These models assume that economic agents have already determined the amount to be spent on foreign tourism and then estimate the sensitivity of a destination's share of the international tourism budget to changes in various determinants, especially income and relative prices among different destinations. The simultaneous-equations approach appears to be perfectly suitable for our purpose of investigating an economy's relative competitiveness in the international tourism market. However, data on each origin's per capita tourism expenditure in Taiwan, Hong Kong, and the ASEAN Five would be needed if the models based on AIDS were to be used in this paper. Unfortunately, the absence of this degree of disaggregated data precludes us from using the existing models. Following Tsai and Wang (1998), we will therefore develop an alternative model in this section to overcome this problem.

An economic agent makes a tourism decision in a number of stages. With given money income and other types of constraints such as time, the agent first decides, via utility maximization, the allocation of expenditure among groups of commodities including tourism. If the economic agent decides to travel, at the second stage, he or she then has to consider whether to travel abroad or domestically. A further stage is the decision to travel to North America, South America, Western Europe, Eastern Europe, Africa, or the Asia-Pacific region. Finally, if the agent does choose the Asia-Pacific region, he or she has to choose which particular country or countries to visit. This decision-making process can be formulated in a two-stage decision.

Let $I, L_{i}$, and $K_{i}$ denote the total number of origins, total economic agents in origin $i$, and the total potential destinations for visitors from origin $i$, respectively. Assume that the preferences of an economic agent $l$ in origin $i$ can be described by the following utility function

$$
u_{l i}=u_{l i}\left(\mathbf{t}_{\mathrm{li}}, \mathbf{x}_{\mathrm{li}}\right), \quad l=1, \ldots, L_{i}, \quad i=1, \ldots, I,
$$

where $\mathbf{t}_{\mathrm{li}}=\left(t_{l i}^{1}, t_{l i}^{2}, \ldots, t_{l i}^{K_{i}}\right)$ is a vector of $K_{i}$ foreign tourism services and $\mathbf{x}_{\mathbf{l i}}=$ $\left(x_{l i}^{1}, x_{l i}^{2}, \ldots, x_{l i}^{M_{i}}\right)$ is a vector of $M_{i}$ commodities other than foreign tourism services consumed by the agent $l$ in origin $i^{2}$ The expression $t_{l i}^{k}, k=1, \ldots$,

2. Domestic travel is included in the vector $\mathbf{x}_{\mathrm{li}}$ because this paper is interested in the relative competitiveness among the competing destinations, not the choice between domestic and foreign tourism. 
$K_{i}$ stands for the consumption of tourism services in destination $k$ by the agent $l$ from origin $i$. Denoting the given price vectors corresponding to $\mathbf{t}_{\mathrm{li}}$ and $\mathbf{x}_{\mathbf{l i}}$ as $\mathbf{p}_{\mathbf{i}}=\left(p_{i}^{1}, p_{i}^{2}, \ldots, p_{i}^{K_{i}}\right)$ and $\mathbf{q}_{\mathbf{i}}=\left(q_{i}^{1}, q_{i}^{2}, \ldots, q_{i}^{M_{i}}\right)$, the money income of the agent $l$ as $Y_{l i}$, and abstracting from other constraints, we can write the utility maximization problem of this agent as

$$
\max u_{l i}=u_{l i}\left(\mathbf{t}_{\mathbf{l i}}, \mathbf{x}_{\mathbf{l i}}\right), \quad \text { s.t. } \quad \mathbf{p}_{\mathbf{i}} \cdot \mathbf{t}_{\mathbf{l i}}+\mathbf{q}_{\mathbf{i}} \cdot \mathbf{x}_{\mathbf{l i}}=Y_{l i} .
$$

If the group of foreign tourism services is weakly separable from $x_{l i}$, then the utility function (1) can be written as

$$
u_{l i}\left(\mathbf{t}_{\mathrm{li}}, \mathbf{x}_{\mathrm{li}}\right)=u_{l i}\left(v_{l i}\left(\mathbf{t}_{\mathrm{li}}\right), \mathbf{x}_{\mathrm{li}}\right),
$$

where $v_{l i}\left(\mathbf{t}_{\mathrm{ii}}\right)$ is a subutility function. If the subutility function $v_{l i}\left(\mathbf{t}_{\mathrm{li}}\right)$ is further assumed to be homothetic, then it is well known from consumer theory that a price index $r$ for the "composite commodity" $v_{l i}$ can be defined, and the consumption decision can be treated as taking place in two stages. ${ }^{3}$ In the first stage, the agent chooses the consumption of the composite commodity $v_{l i}$ along with other commodities $\mathbf{x}_{\mathrm{li}}$. This in turn determines the expenditure to be spent on the commodity $v_{l i}$, say $Y_{l i}^{t}=r v_{l i}$. In the second stage, the agent chooses optimal $t_{l i}^{k}, k=1, \ldots, K_{i}$ by solving the following optimization problem:

$$
\max v_{l i}\left(\mathbf{t}_{\mathrm{li}}\right) \quad \text { s.t. } \quad \mathbf{p}_{\mathbf{i}} \cdot \mathbf{t}_{\mathrm{li}}=Y_{l i}^{t} .
$$

The homotheticity of $v_{l i}\left(\mathbf{t}_{\mathrm{li}}\right)$ implies that the ordinary demand function of $t_{l i}^{k}$, $k=1, \ldots, K_{i}$ is

$$
t_{l i}^{k}=Y_{l i}^{t} b_{l i}^{k}\left(\mathbf{p}_{\mathbf{i}}\right) .
$$

Based on the popular assumption in the international trade literature that preferences are identical for all consumers in a country, the total demand of the origin $i$ for tourism services in destination $k$ is

$$
\sum_{l} t_{l i}^{k}=b_{i}^{k}\left(\mathbf{p}_{\mathbf{i}}\right)\left(\sum_{l} Y_{l i}^{t}\right)
$$

Multiplying both sides of equation (6) by $p_{i}^{k}$, summing over $k$, and using the fact that $\sum_{k} p_{i}^{k} \sum_{l} t_{l i}^{k}=\sum_{l} Y_{l i}^{t}$ gives us $\sum_{k} p_{i}^{k} b_{i}^{k}=1$. The share of the total foreign tourism expenditure of origin $i$ on the tourism services of destination $k$ can thus be defined as

3. Theoretically, the assumption of homotheticity requires an economic agent to consume all of the foreign tourism services available in the model. Since the economic agent normally makes a discrete choice among destinations, the assumption may be inappropriate if he or she does not consume at least one of the foreign tourism services. Nevertheless, the assumption does make sense for a country as a whole. In addition, it warrants mentioning that the homotheticity assumption is a sufficient, but not necessary, condition for the two-stage budgeting argument. Nevertheless, this assumption could greatly simplify the utility-maximizing process and so is widely accepted in both theoretical and applied analyses (Varian, 1992, 150-51). 


$$
\beta_{i}^{k}\left(\mathbf{p}_{\mathbf{i}}\right)=\frac{p_{i}^{k} b_{i}^{k}\left(\mathbf{p}_{\mathbf{i}}\right)}{\sum_{j=1}^{K_{i}} p_{i}^{j} b_{i}^{j}} .
$$

The evolution of $\beta_{i}^{k}$ can be used to indicate the change in relative competitiveness of destination $k$ among the $K_{i}$ destinations competing for visitors from origin $i$. Noticeably, an increase in the relative competitiveness of a destination must lead to a decrease in the competitiveness of some other destinations because $\sum_{k} \beta_{i}^{k}=1$.

Although the change in relative competitiveness is important in itself, we are more interested in identifying the factors that determine the time profile of $\beta_{i}^{k}$. For that purpose, a parameter $\alpha_{i}$ is introduced to capture the change in preferences, so that $\beta_{i}^{k}\left(\mathbf{p}_{\mathbf{i}}\right)$ is modified as $\beta_{i}^{k}\left(\mathbf{p}_{\mathbf{i}}, \alpha_{i}\right)$. Aside from varying with the passage of time, $\alpha_{i}$ can be "induced" to change by supplyside factors such as improved infrastructure or enhanced promotional campaigns in the destinations. Hence, $\beta_{i}^{k}\left(\mathbf{p}_{\mathbf{i}}, \alpha_{i}\right)$ becomes $\beta_{i}^{k}\left(\mathbf{p}_{\mathbf{i}}, \alpha_{i}(T, \mathbf{z})\right)$, with $T$ standing for time trend and $\mathbf{z}$ for a vector of supply-side factors. Using the fact that $\beta_{i}^{k}$ is homogeneous of degree zero in $\mathbf{p}_{\mathrm{i}}$, after some manipulation, equation (7) can be expressed in terms of the rate of change from the base year

$$
G \beta_{i}^{k}=\sum_{j \neq k}^{K_{i}} \theta_{i j}^{k}\left(G p_{i}^{j}-G p_{i}^{k}\right)+\varepsilon_{i}^{k} G T+\sum_{n} \eta_{i n}^{k} G z_{n}
$$

where

$$
G x=\frac{x-x^{0}}{x^{0}}, \quad x=\beta_{i}^{k}, p_{i}^{j}, T, z_{n} ;
$$

$x^{0}$ being the base-year value of $x$,

$$
\begin{aligned}
\theta_{i j}^{k} & =\frac{\partial \beta_{i}^{k}}{\partial p_{i}^{j}} \frac{p_{i}^{j 0}}{\beta_{i}^{k 0}}, \\
\varepsilon_{i}^{k} & =\frac{\partial \beta_{i}^{k}}{\partial T} \frac{T^{0}}{\beta_{i}^{k 0}}, \\
\eta_{i n}^{k} & =\frac{\partial \beta_{i}^{k}}{\partial z_{n}} \frac{z_{n}^{0}}{\beta_{i}^{k 0}} .
\end{aligned}
$$

While the prices $p_{i}^{j}, j=1, \ldots, K_{i}$ are expressed in the currency of origin $i$, visitors generally have to pay for tourism services whose prices are denominated in the currencies of the destinations. The exchange rate between the currency of destination $j$ and that of origin $i$ is needed to obtain $p_{i}^{j}$. Let the price of tourism services in terms of destination $j$ 's currency be $p_{i}^{* j}$, and $E_{i}^{j}$ is the exchange rate of one unit of currency $j$ in terms of currency $i$. Then $p_{i}^{* j}$. 
$E_{i}^{j}=p_{i}^{j}$. Taking $\log$ differentiation for any $j$ and $j \neq k$ respectively, and subtracting the latter from the former, yields

$$
\left(G p_{i}^{* j}-G p_{i}^{* k}\right)+\left(G E_{i}^{j}-G E_{i}^{k}\right)=G p_{i}^{j}-G p_{i}^{k},
$$

where the notation $G x$ denotes the rate of change of the variable $x$. Equation (9) reveals that, for visitors from origin $i$, the rate of change in the relative cost of traveling to destination $j$ versus destination $k$ consists of two parts: one from the change in the price of tourism services in each destination, the other from the variation in exchange rates. If visitors have equal access to the information on foreign prices as well as exchange rates and treat them in exactly the same way, then equation (9) can be substituted directly into equation (8).

However, research on the economics of international tourism indicates that visitors generally have better access to information on exchange rates than on prices in the destinations, implying that visitors tend to be more sensitive to changes in exchange rates than those of prices (Artus 1972; Truett and Truett 1987; Crouch 1992; Moshirian 1993). ${ }^{4}$ In such circumstances, the variations in exchange rates in the model have to be incorporated as separate variables, and equation (8) becomes

$$
G \beta_{i}^{k}=\sum_{j \neq k}^{K_{i}} \theta_{i j}^{k}\left(G p_{i}^{* j}-G p_{i}^{* k}\right)+\sum_{j \neq k}^{K_{i}} \xi_{i j}^{k}\left(G E_{i}^{j}-G E_{i}^{k}\right)+\varepsilon_{i}^{k} G T+\sum_{n} \eta_{i n}^{k} G z_{n} .
$$

\subsection{Data Description}

\subsubsection{The Sample}

The model developed in section 10.2 describes the way economic agents of a particular origin allocate their foreign tourism budget among various destinations. A decrease (an increase) in the share $\beta_{i}^{k}$ implies that destination $k$ is losing (gaining) the tourism market in origin $i$. Because the main aim of this paper is to study and compare determinants of competitiveness of international tourism in the Southeast Asian region, the group of destinations in the subutility function is made up of Taiwan, Hong Kong, and the ASEAN Five.

As far as the origins are concerned, one problem is that the destinations, although they compete with each other, may export their tourism services to quite different markets. For example, during 1991-92, Japan was always among the top two origins for all the seven destinations; however, the United States was the second largest origin for Taiwan, and Aus-

4. When there is a significant change in exchange rates, the long-run adjustment could mean that both domestic and foreign prices change in the same proportion. Therefore, how prices are quoted may not be important to international tourists. 
tralia was the second largest origin for Singapore. Another problem concerns the importance of intragroup tourism; the top origin for Indonesian tourism is Singapore, whereas it is estimated that some three-quarters of foreign visitors to Malaysia are from the ASEAN region. Accordingly, to have a meaningful test on the relative competitiveness, this paper has to (a) limit the origins to those importing a significant proportion of the tourism services from each of the destinations and (b) exclude all the origins that are themselves among the destinations to avoid complications from choosing between domestic and foreign tourism. With these considerations in mind, the United States and Japan are chosen as the two origins. ${ }^{5}$ Consequently, for each origin the first sample (hereafter, sample 1) consists of seven destinations. Moreover, on the basis of data quality, three other subsamples will be analyzed for each destination. For the destinations of Taiwan, Hong Kong, and Singapore, sample 2 takes Malaysia, for which the data are the most problematic, out of sample 1; sample 3 further deletes Indonesia and the Philippines from sample 2; sample 4 has only the three newly industrialized economies (Taiwan, Hong Kong, and Singapore) in it. For the destination of Malaysia, sample 2 takes Taiwan out of sample 1; sample 3 further deletes the Philippines and Thailand from sample 2; sample 4 has only Hong Kong, Singapore, and Malaysia in it. For the destination of Indonesia, sample 2 takes the Philippines out of sample 1; sample 3 further deletes Taiwan and Hong Kong from sample 2; sample 4 has only Singapore, Malaysia, and Indonesia in it. For the destination of the Philippines, sample 2 takes Malaysia out of sample 1; sample 3 further deletes Indonesia and Thailand from sample 2; sample 4 has only Taiwan, Hong Kong, and the Philippines in it. For the destination of Thailand, sample 2 takes the Philippines out of sample 1; sample 3 further deletes Singapore and Indonesia from sample 2; sample 4 has only Taiwan, Hong Kong, and Thailand in it (please refer to table 10.1). The period to be covered spans over twentytwo years, from 1973 to 1994, during which continuous time series data are available for all the economies under examination. ${ }^{6}$ It is noteworthy that a span of twenty-two years is far above the average time period, thirteen years, in the existing empirical studies of international tourism literature (Crouch and Shaw 1990).

5. In fact, the same empirical procedure has also been tried for other origins (such as the United Kingdom, Germany, and Australia), and the empirical results are somewhere between those of the United States and Japan. For the purpose of simplicity, only two extremes are chosen for this paper. Nevertheless, the empirical results of the other three origins are available upon request from the authors.

6. It might have been desirable to extend the data period up to 1999 in order to include the effect of the Asian financial crisis in the study. Unfortunately, the needed data set has been updated only until 1997 due to some data-collecting problems. Therefore, the investigation of the Asian financial crisis effect must wait for future study. 
Table 10.1

Subsamples' Components for Seven Destinations

\begin{tabular}{|c|c|c|c|c|}
\hline \multirow[b]{2}{*}{ Destination } & \multicolumn{4}{|c|}{ Subsample } \\
\hline & Sample 4 & Sample 3 Add: & Sample 2 Add: & Sample 1 Add: \\
\hline Taiwan & Taiwan & \multirow[t]{3}{*}{ Thailand } & Indonesia & \multirow[t]{3}{*}{ Malaysia } \\
\hline Hong Kong & Hong Kong & & The Philippines & \\
\hline Singapore & Singapore & & & \\
\hline \multirow[t]{3}{*}{ Malaysia } & Hong Kong & \multirow[t]{3}{*}{ Indonesia } & The Philippines & \multirow[t]{3}{*}{ Taiwan } \\
\hline & Singapore & & Thailand & \\
\hline & Malaysia & & & \\
\hline \multirow[t]{3}{*}{ Indonesia } & Singapore & \multirow[t]{3}{*}{ Thailand } & Taiwan & \multirow[t]{3}{*}{ The Philippines } \\
\hline & Malaysia & & Hong Kong & \\
\hline & Indonesia & & & \\
\hline \multirow[t]{3}{*}{ The Philippines } & Taiwan & \multirow[t]{3}{*}{ Singapore } & Indonesia & \multirow[t]{3}{*}{ Malaysia } \\
\hline & Hong Kong & & Thailand & \\
\hline & The Philippines & & & \\
\hline \multirow[t]{3}{*}{ Thailand } & Taiwan & \multirow[t]{3}{*}{ Malaysia } & Singapore & \multirow[t]{3}{*}{ The Philippines } \\
\hline & Hong Kong & & Indonesia & \\
\hline & Thailand & & & \\
\hline
\end{tabular}

\subsubsection{The Variables}

\section{Dependent Variable}

According to the theoretical model in the last section, the dependent variable $\left(\beta_{i}^{k}\right)$ represents destination $k$ 's share of total foreign tourism expenditure of origin $i$. Unfortunately, with very few exceptions, this information is simply nonexistent (Moshirian 1993). In practice, most economies estimate tourism receipts by multiplying the number of tourists, average length of stay, and average expenditure per day. As the data on the average length of stay and average daily expenditure are derived from sample surveys, they are not as reliable as the data on visitor arrivals, which are gathered from the arrival and departure cards. In some cases, visitor arrivals are even the only data available. Consequently, each destination's share of the total visitor arrivals at all the destinations in each sample from a given origin will be used as the proxy variable for the dependent variable $\beta_{i}^{k} .7$ The sources for the data on visitor arrivals by residence are from various issues of Annual Statistical Report by Pacific Asia Travel Association

7. It is admitted that this can hardly be an ideal exercise. Variations in the average length of stay and average daily expenditure are usually too large to be ignored. However, until sufficient and reliable information is available, it might be the best choice. This also explains why the majority of the extant studies use the number of visitor arrivals and departures in the analysis. In addition, because different foreign visitors may come to a destination for different purposes (such as sightseeing, business, visiting relatives, attending conferences, studying abroad, and others), their motivations and economic sensitivities vary considerably. Ideally, the same regression analysis should be run for different groups of foreign visitors. However, data on each different groups of foreign visitors are fragmental for most destinations in this study. 
(PATA), which are supplemented by the data from Yearbook of Tourism Statistics of the World Trade Organization (WTO) and country-specific sources.

\section{Independent Variables}

Two sets of independent variables appear in equation (10). With seven destinations, the first set is composed of six rates of change in relative prices, whereas the other set includes variables affecting tourists' preferences. Since international tourism is an amalgam of goods and services, its price is a much more complex construct than that of any other produce. It is made up of three key elements: the price of transport services to the destination(s), the prices of goods and services purchased in the destination(s), and exchange rates. Although a tourism price defined as a function of the three components for each destination is theoretically desirable, the consumer price index (CPI) is the most popular one used in empirical studies. Some researchers have questioned the legitimacy of using the CPI in this particular context and have attempted to construct a tourist price index (Martin and Witt 1987; Moshirian 1993). However, the results are not as exciting as one would expect. In their conclusions, Martin and Witt admitted, "This study does not provide evidence of clear superiority [of a tourist price index], but rather indicates that the consumer price index, either alone or together with the exchange rate, is a reasonable proxy for the cost of tourism." Therefore, CPI in each destination is used as the proxy for the price of tourism services in that country. Data on the CPI and exchange rate of Taiwan come from the Taiwan Statistical Data Book 1995, whereas those of Hong Kong are from the World Bank's World Tables 1992 as well as Hong Kong Digest of Statistics, February 1995. The sources for the CPI and exchange rate of all the other destinations are the International Monetary Fund's International Financial Statistics Yearbook from 1994 and International Financial Statistics, September 1995. All the CPIs are converted so that 1990 is the base year. ${ }^{8}$

The first preferences-related variable is the time trend. It is frequently included in regression analysis to account for exogenous changes in preferences (O’Hagan and Harrison 1984; White 1985; Crouch and Shaw 1990). On the other hand, supply-side factors such as marketing expenditure or a location's innate physical attractiveness or improvement in infrastructure might well induce changes in tastes. Marketing expenditure is of particular

8. Transport costs are not taken into account in the analysis, although their importance cannot be denied in any sense. The main reason is the lack of satisfactory information for the whole period of 1973 to 1994 and from some destinations (especially Malaysia, Indonesia, the Philippines, and Thailand). However, this could be justified on the basis of the geographical proximity of the seven destinations. The difference in distance from the United States or Japan to any of the destinations seems not significant enough to affect the relative prices to the extent that a switch in the ranking of tourism costs among the destinations indeed occurs. 
importance in a study concerning competitiveness. For instance, it is widely held that the recent boom of international tourism in Southeast Asia has been the result of the very active promotion by member states of ASEAN (Hitchcock, King, and Parnwell 1993). Similarly, a location's innate physical attractiveness for tourists is also an important determinant of an economy's competitiveness in international tourism. However, the fragmented data on marketing expenditure and the dearth of an objective measure of the location's innate physical attractiveness prevent us from including these variables in the statistical analysis. In equation (10), the supply-side factors are formulated to include only what can be reasonably quantified (or, more precisely, differentiable). Nevertheless, there are well-known qualitative (discrete) variables that tend to have extremely strong, though perhaps short-lived, impacts on international tourism. Some typical examples of such disturbances are political or social disorder, travel or foreign exchange restrictions, and special events like the Olympic Games. Following the standard procedure, we will use dummy variables to account for such events. After examining the available information, we will include four dummy variables in our empirical analysis. They are defined as

$$
\begin{aligned}
& D 79=\left\{\begin{array}{l}
1, \text { for year } 1979 \text { after the United States terminated its official } \\
\text { relationship with Taiwan in late } 1978 \\
0, \text { other years }
\end{array}\right. \\
& D 794=\left\{\begin{array}{l}
1, \text { for China's open-door policy, } 1979-94^{9} \\
0, \text { other years }
\end{array}\right. \\
& D 83=\left\{\begin{array}{l}
1, \text { for } 1983-94, \text { referring to the social-political disorder in } \\
\text { the Philippines after Aquino's assassination in August } 1983 \\
0, \text { other years }
\end{array}\right. \\
& D 90=\left\{\begin{array}{l}
1, \text { for Visit Malaysia Year in } 1990 \\
0, \text { other years. }
\end{array}\right.
\end{aligned}
$$

Since there is a high degree of correlation between almost every pair of the rate of change in relative prices, a single relative price for each destination is

9. However, an increase in new destinations does not necessarily cause a particular destination to lose its market, since there might be complementarity between the newcomers and the established one. 
used instead to avoid multicollinearity. Following White (1985) and O'Hagan and Harrison (1984), we define the relative price of destination $k$ to other destinations faced by visitors from origin $i$ as $r p_{i}^{k}=\left(p_{i}^{k}\right) /\left[\prod_{j \neq k}\left(p_{i}^{j}\right)^{w_{j}}\right]$, where $w_{j}=s_{j} / \sum_{j \neq k} s_{j}$, and $s_{j}$ is destinations except for destination $k$. With this, and with data availability taken into account, equation (10) can be modified to arrive at the following model for empirical studies in this paper:

$(10)^{\prime} G \beta_{i}^{k}=\theta_{i}^{k} G r p_{i}^{* k}+\xi_{i}^{k} G r E_{i}^{k}+\varepsilon_{i}^{k} G T+h_{i 79}^{k} D 79+h_{i 83}^{k} D 83+h_{i 90}^{k} D 90$

$$
+h_{i y 94}^{k} D 794
$$

where $G r p_{i}^{* k}=G p_{i}^{* k}-\sum_{j \neq k} w_{j} G p_{i}^{* j}$ and $G r E_{i}^{k}=G E_{i}^{k}-\sum_{j \neq k} w_{j} G E_{i}^{j}$.

Although the law of demand leads us to expect a negative value for $\theta_{i}^{k}$ in equation $\left(10^{\prime}\right)$, the situation is a little bit subtle in the case of international tourism. Consider an increase in the relative price of destination $k$ (relative to alternative destinations) faced by visitors of origin $i$. Two extreme cases for this to occur are (a) an increase in the price of destination $k\left(p_{i}^{k}\right)$ with the prices in the alternative destinations $\left[\prod_{j \neq k}\left(p_{i}^{j}\right)^{w_{j}}\right]$ remaining constant, and (b) a decrease in the prices of alternative destinations with the price in destination $k$ staying intact. In the first case, $\theta_{i}^{k}$ would as usual be expected to be negative. In the second case, depending on whether destination $k$ and the alternative destination(s) are substitutes or complements, $\theta_{i}^{k}$ could be negative or positive. It becomes even more difficult to assign $\theta_{i}^{k}$ when both $p_{i}^{k}$ and $\left[\prod_{j \neq k}\left(p_{i}^{j}\right)^{w_{j}}\right]$ change. However, given that the ASEAN Five tends to be treated as a unit and Hong Kong is closer to Taiwan in many respects, it is hypothesized that visitors regard Taiwan and the alternative destinations as substitutes, so that $\theta_{i}^{k}$ should be negative. A similar argument is applicable to the sign of $\xi_{i}^{k}$.

As far as the time trend and the dummy variables are concerned, figure 10.5 reveals that Taiwan has been losing its market share compared to other East Asia/Pacific countries since the mid-1970s. Therefore, $\varepsilon_{i}^{k}$ ought to be negative if there is an autonomous switch in preferences away from Taiwan. The social political disorder in the Philippines since Aquino's assassination in 1983 necessarily discourages visitors from going to that country. As argued above, Taiwan and ASEAN are, if anything, more likely to be substitutes than complements, leading us to expect a positive coefficient for $D 83$. The story is just the opposite for the coefficient of $D 90$, which marks the extremely successful campaign of the Visit Malaysia Year in 1990. China's open door to foreigners has certainly had a tremendous impact on international tourism industry in East Asia, given its unique natural and cultural heritage. Although all the destinations in this study might well be affected by this policy, Taiwan would doubtless bear the highest cost, for it shares very similar tourism resources with China. As a result, the coefficient for D794 ought to be negative. The termination of the official diplomatic relationship with the United States in late 1978 should have adversely affected 
U.S. visitors to Taiwan, implying a negative sign for $h_{i 79}^{k}$ when the origin is the United States.

\subsection{Empirical Results}

\subsubsection{Estimation Procedure}

The literature of international finance indicates that the linkage between domestic currency and foreign prices may be close. Thus, the pricing of tour packages may change when there is an exchange rate change. Then, there may exist an induced problem from the multicollinearity relationship among independent variables in the regression analysis. To avoid the multicollinearity problem, the variance inflationary factor (VIF) is first used to test the degree of multicollinearity among independent variables. The results show that there is no serious multicollinearity problem in our data because the VIF values of all independent variables for the destinations of Taiwan, Hong Kong, Malaysia, and Thailand are all below 5, those for Indonesia and the Philippines are close to 10, and that for Singapore is little higher than 10 in the U.S. market; those for Taiwan, Hong Kong, and the Philippines are 5.538, 6.214, and 6.116, respectively, and those for other destinations are all below $5 .{ }^{10}$ Since the theoretical model of this paper deals with all destinations for a given origin at the same time, the appropriate estimation method is the simultaneous-equations approach. Specifically, the three-stage least squares (3SLS) method is used to estimate the parameters of equation $\left(10^{\prime}\right)$ for all destinations simultaneously with respect to each origin. ${ }^{11}$ Tables 10.2 and 10.3 report the empirical results for the United States and Japan, respectively. Although the $R^{2}$ statistics obtained by the ordinary least squares (OLS) method is presented in each equation, it should be cautioned that specification testing at the system level is more problematic than that for the single equation (O'Hagan and Harrison 1984). Therefore, the corresponding $R^{2}$ is added just for the purpose of reference.

\subsubsection{Empirical Findings}

\section{The U.S. Market}

The regression results of seven destinations in the U.S. market for samples $1-4$ show that the estimation result of sample 1 is almost the same

10. The VIF value is equal to 1 for each independent variable with no correlation with each other, but the VIF value may be even more than 10 for the independent variable highly correlated with others. However, the multicollinearity problem would only increase standard deviations of estimates and reduce their significance levels even if it exists.

11. The full information maximum likelihood (FIML) method has also been used in this study. However, about half of the cases do not converge. Incidentally, the parameter estimates for other destinations are not reported, but they are available upon request from the authors. 
as those of samples 2-4; however, the former is better than the latter from the statistical point of view. Therefore, only seven destinations' regression results of sample 1 will be presented in table 10.2. ${ }^{12}$ The estimated coefficients of $G r p_{i}^{* k}$ for Hong Kong, Malaysia, the Philippines, and Thailand are negative as expected and reach at least the 10 percent significance level. Those for Taiwan and Singapore are not significantly different from zero. Available tourism statistics reveal that the majority of U.S. visitors to Taiwan and Singapore are traveling for business purposes or visiting relatives are overseas Chinese. The former group is well known to be less price elastic. In addition, most of the homecoming overseas Chinese stay with their relatives and thus are generally not sensitive to price fluctuations. Consequently, the relative price change has no significant impact on U.S. visitors to Taiwan and Singapore. However, the estimated coefficient of $\operatorname{Grp}_{i}^{* k}$ for Indonesia is positive at the 1 percent significance level. One possible reason for this finding is that, depending on the way relative prices change as well as whether Indonesia and other destinations are substitutes or complements, the coefficient of $G r p_{i}^{* k}$ could be of any direction. Table 10.2 shows that Indonesia and the Philippines might be complements in the U.S. market. ${ }^{13}$ As a consequence, it is reasonable to expect that the relative price changes have a significantly positive impact on the U.S. visitors to Indonesia. By referring to Gujarati (1988, 178-82) as well as Pindyck and Rubinfeld (1981, 128-30), we conclude that the other likely explanation for the perverse result is that some important explanatory variables such as travel costs, which of course are not reflected in Indonesian CPI, are missing from the empirical model in this study. Hence, the significantly positive coefficient of $G r p_{i}^{* k}$ might just capture the effect of the almost monopolized air fares between Indonesia and the United States. Without doubt, there is no easy way to test this proposition until appropriate data are available.

The estimated coefficients of $G r E_{i}^{k}$ for Malaysia and Thailand have the expected (negative) signs. Those for Taiwan, Hong Kong, Singapore, and Indonesia are not significantly different from zero due to the fact that a considerable part of the travel expenses in these destinations is priced in U.S. dollars rather than local currencies. Nevertheless, surprisingly, the coefficient of $G r E_{i}^{k}$ for the Philippines is positive and reaches the 10 percent significance level. The perverse exchange rate effect could be due to omission of some relevant explanatory variables, such as the aggregate economic condition or foreign direct investment, that are correlated with $G r E_{i}^{k}$ and might have a significantly positive impact on the U.S. visitors to the Philippines. Accordingly, the significantly positive coefficient of $G r E_{i}^{k}$ might absorb the effects of omitted variables.

12. The regression results of seven destinations in the U.S. market for samples $2-4$ are available upon request.

13. One possible reason for this result is that U.S. tourists visit both countries in the same trip. 


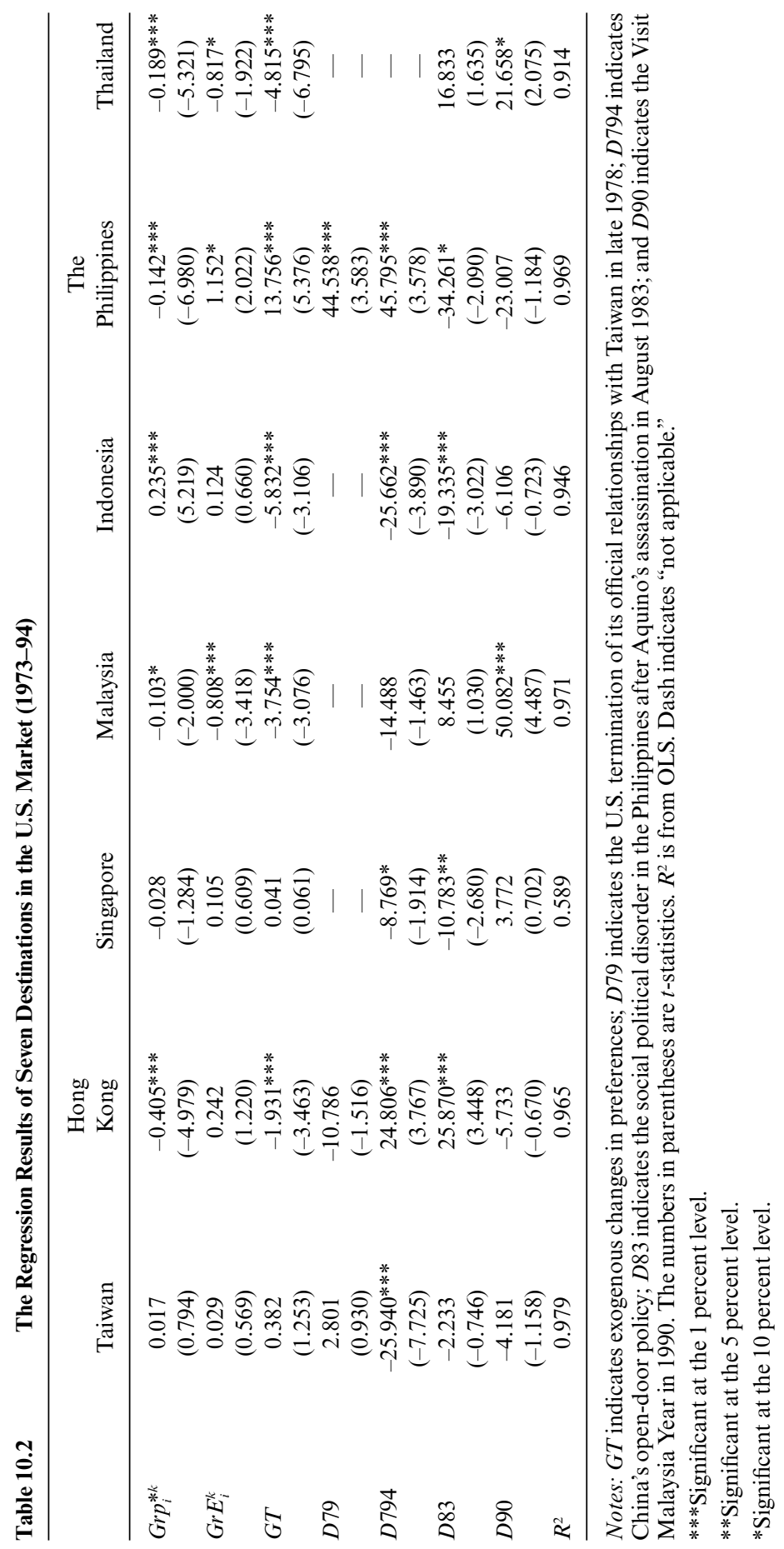


The most puzzling findings from table 10.2 are that the estimated coefficients of the rate of change in time trend $(G T)$ for Hong Kong, Malaysia, Indonesia, and Thailand are negative at the 1 percent significance level. This implies that there is an autonomous switch in preferences away from the above four economies. The estimated coefficient of GT for the Philippines is positive at the 1 percent significance level, implying that there is an autonomous switch in preferences for the Philippines. Surprisingly, those for Taiwan and Singapore are not significantly different from zero. One possible reason for the above findings is that figure 10.5 is a synthesized product of multiple factors.

The estimated coefficient of $D 79$ is positive and highly significant only for the Philippines, but those for other Southeast Asian economies are not significantly different from zero. This may imply that Taiwan and the Philippines are substitutes for each other in the U.S. market.

The most striking, though not surprising, findings from table 10.2 are that the estimated coefficients of D794 for Taiwan, Singapore, and Indonesia are negative and reach at least the 10 percent significance level. This result confirms the belief that the open-door policy adopted by China has had an adverse impact on international tourism in Taiwan, and it may imply that China is also a substitute for Singapore or Indonesia in the U.S. market. As clearly demonstrated in table 10.2, this is definitely the single most important factor responsible for the dramatic decline of Taiwan's market share in the U.S. market during the past fifteen years. Not only does it dominate the diplomatic setback between the United States and Taiwan (D79) in determining the relative competitiveness of the latter in the U.S. market, but it also helps clarify the false impression that there are "autonomous" changes in preferences $(G T)$ among the U.S. visitors to switch away from Taiwan. On the contrary, the highly significant positive coefficients of $D 794$ for Hong Kong and the Philippines imply that China is a complement for them in the U.S. market, and they are beneficiaries of the Chinese opendoor policy.

As to the coefficient of $D 83$, it is significantly negative for Singapore, Indonesia, and the Philippines, implying that the Philippines and Singapore (or Indonesia) seem to be complements in the U.S. market; however, it is positive and highly significant for Hong Kong, implying that Hong Kong and the Philippines are substitutes for U.S. tourists. ${ }^{14}$ Overall, while the social-political disorder after Aquino's assassination did deter U.S. visitors from going to the Philippines, its single biggest beneficiary is Hong Kong.

The estimated coefficients of $D 90$ are positive and significant at the 1 percent and 10 percent levels, respectively, for Malaysia and Thailand, imply-

14. This accords with the finding of Chu (1993), which show that the Philippines and Hong Kong are close substitutes for international tourists. 
ing that Malaysia did a very successful campaign in 1990, and Thailand is another beneficiary of the event in the Southeast Asian region. In addition, the very successful campaign of the Visit Malaysia Year in 1990 only slightly affected other economies' shares of U.S. visitors, as revealed by the regression results of table 10.2.

\section{The Japan Market}

The regression results of seven destinations in the Japan market for samples 1-4 also show that the signs of all corresponding coefficients in sample 1 are the same as those in samples 2-4; nevertheless, the former are statistically better than the latter. Hence, only seven destinations' regression results of sample 1 will be presented in table 10.3. ${ }^{15}$ It turns out that the results are very different from those of the United States. The estimated coefficient of $\operatorname{Grp}_{i}^{* k}$ for all the destinations is insignificantly different from zero, except that for Singapore.

Two distinct behavior patterns between U.S. and Japanese visitors might be responsible for this finding: one is the difference in the purposes of visit (including sightseeing, business, visiting relatives, attending conference, studying abroad, and others), and the other is the difference in the patterns of travel (including packaged group tours and personal nongroup tours). The top two purposes for Japanese visitors to the Southeast Asian region are sightseeing and business. ${ }^{16}$ By contrast, the first two purposes for U.S. visitors to the region are business and visiting relatives. ${ }^{17}$ As far as the patterns of travel are concerned, most Japanese visitors with the purpose of sightseeing came with packaged group tours; most U.S. visitors with the purpose of business or visiting relatives came with personal nongroup tours. The packaged group tours are run by travel agencies, which generally have a better bargaining position for all kinds of tourism expenditures and have a long-term contract with local tourism-related firms in the destinations. Hence, variations in the relative price levels do not have any significant correlation with most of the Southeast Asian destinations' market shares in the Japan market. However, the positive correlation between the market share and the relative price for Singapore is beyond expectation. Yet it is noticeable that their absolute values are all smaller than the corresponding coefficient of $G r E_{i}^{k}$ in each sample, implying that the combined price and exchange rate effect might well be consistent with the law of demand. As in the case of U.S. visitors to Indonesia, there are two possible reasons for the significantly positive coefficient of $G r p_{i}^{* k}$ in table 10.3. The first is

15. The regression results of seven destinations in the Japan market are available upon request.

16. For instance, about 70 percent and 20 percent of Japanese visitors to Taiwan are there for sightseeing and business, respectively, both in 1993 and 1994 (Tsai and Wang 1998).

17. For example, some 40 percent and 30 percent of U.S. visitors to Taiwan are there for business and to visit relatives, respectively, both in 1993 and 1994 (Tsai and Wang 1998). 


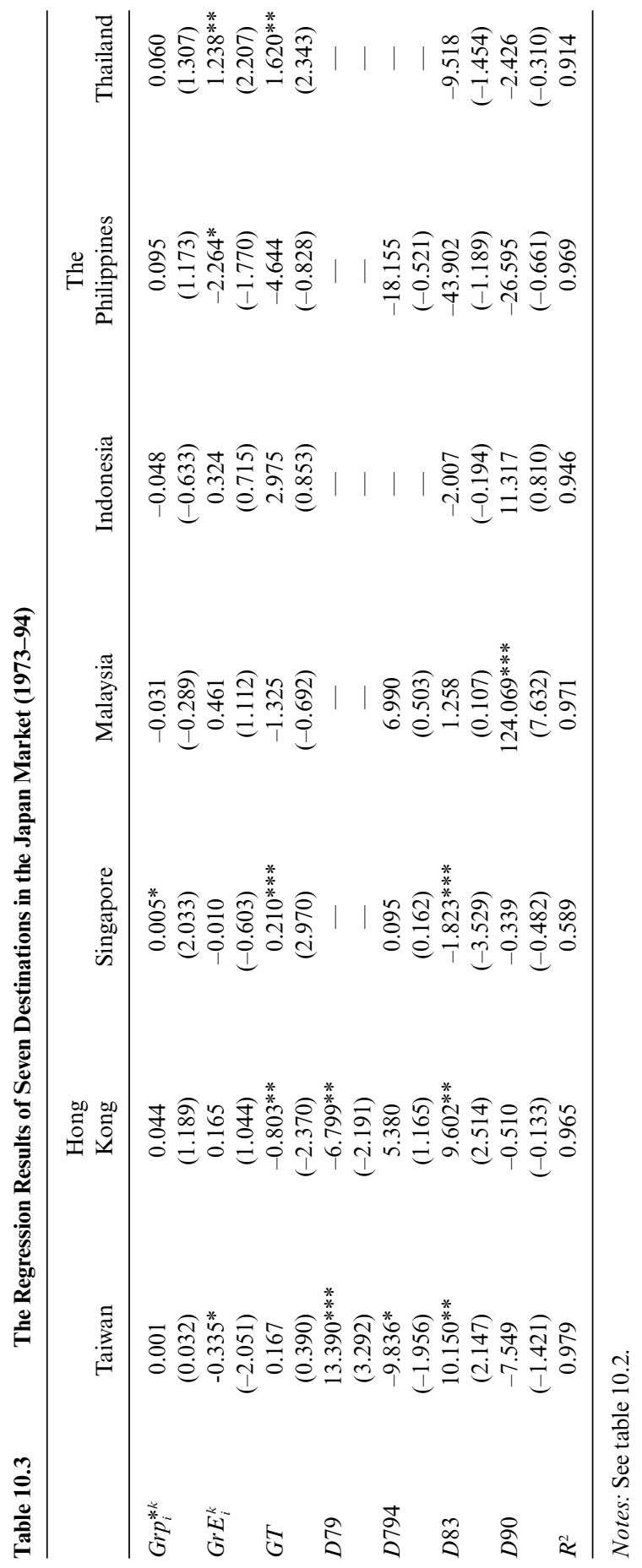


that, depending on the way relative prices change as well as whether Singapore and other destinations are substitute or complements, the coefficient of $\mathrm{Grp}_{i}^{* k}$ could be of any direction. Although table 10.3 shows that Singapore and the Philippines might be complements in the Japan market, no further convincing evidence could be given to support that Japanese visitors to Singapore have treated Singapore and the other destinations under study as complements. ${ }^{18}$ The second likely explanation for the perverse price effect is that some important explanatory variables such as air fares, which account for more than 50 percent of the tourism expenditures of the Japanese visitors to Singapore and are not reflected in Singapore's CPI, are missing from the empirical model. As a result, the positive coefficient of Grp ${ }_{i}^{* k}$ might capture the effect of the almost monopolized air fares between Singapore and Japan. Again, this proposition cannot be easily tested without appropriate data.

With reference to the estimated coefficient of $G r E_{i}^{k}$ in the Japan market, it is significantly negative for Taiwan and the Philippines, but insignificantly different from zero for Hong Kong, Singapore, Malaysia, and Indonesia. The reason for the former is that the tourism expenditures in Taiwan and the Philippines are priced in terms of U.S. dollars only. Therefore, in contrast to the case of U.S. visitors, the variation in exchange rates affects Japanese visitors to Taiwan and the Philippines adversely. This result corroborates those widely found in the international tourism literature (Truett and Truett 1987; Crouch 1992). On the other hand, one possible reason for the latter finding is that the tourism expenditures in Hong Kong, Singapore, Malaysia, and Indonesia may also be priced in terms of Japanese yen in addition to U.S. dollars. As a result, just as in the case of U.S. visitors, the variation in exchange rates does not significantly affect Japanese visitors to Hong Kong, Singapore, Malaysia, and Indonesia. Beyond expectation, the estimated coefficient of $\mathrm{Gr} E_{i}^{k}$ for Thailand is positive at the 5 percent significance level. Again, the likely explanation for the perverse exchange rate effect is the same as that in table 10.2.

Table 10.3 shows that Hong Kong lost some of its market share and Singapore and Thailand gained some market shares during the past two decades because of the changes in preferences among Japanese visitors. By examining the tourism statistics, we find that there is a clear trend for Japanese tourists to switch from Hong Kong to Singapore after 1980. There is some evidence showing that the change in the age structure among Japanese visitors might have played a crucial role in this matter. Japanese visitors have been getting younger and younger all the time. However, to what extent the preferences of the younger generations differ from those of the

18. One possible piece of evidence to support the complementarity between Singapore and the Philippines is that most Japanese visitors come to both countries in the same trip. However, available data on the above evidence have been incomplete. 
older ones and thus contribute to the gain of Singapore's and the loss of Hong Kong's competitiveness in the Japanese market is certainly a topic worth further investigation.

As far as D79 and D794 are concerned, the estimated coefficient of D79 for Taiwan in the Japan market is positive and highly significant, but that for Hong Kong is significantly negative. Two possible reasons might be responsible for the above finding. One is that Taiwan and Hong Kong are substitutes in the Japanese market because of cultural similarity. The other is that the promotion effort of Taiwan was focused on the Japanese market in 1979 after the United States terminated its official relationship with Taiwan in late 1978. These two factors might explain why Taiwan gained its share and Hong Kong lost its share of the Japanese market in 1979. The estimated coefficient of $D 794$ for Taiwan is negative at the 10 percent significance level in samples 1-2, implying that, just as in the case of U.S. tourists, the Chinese open-door policy has had an adverse impact on Taiwan's market share in Japan. Nevertheless, the effect of China's open-door policy is insignificant in samples 3-4 and much less significant than that in the case of U.S. visitors to Taiwan. It is well known that China's attractiveness is mainly based on its abundant cultural and natural heritage. For most visitors from the Western world, such as the United States, ancient Chinese civilization is certainly mysterious and fascinating. Conversely, due to the geographical proximity and long-lasting historical connection with China, the Japanese have a better understanding of and thus less curiosity about mainland China. This, along with the fact that the United States is one of the targeted countries with tourism subsidized by the Chinese government, whereas there is still widespread xenophobia toward Japanese visitors in China, might explain the different reactions to China's open-door policy.

Table 10.3 indicates that the social-political disruption in the Philippines after 1983 has affected Japanese visitors to Taiwan and Hong Kong positively. That is, Taiwan and Hong Kong are beneficiaries from the chaos in the Philippines. Table 10.3 shows that the estimated coefficient of $D 83$ is negative and highly significant, implying that Singapore and the Philippines might be complements for Japanese tourists. ${ }^{19}$ Finally, the estimated coefficient of $D 90$ for Malaysia is positive and extremely significant. This result indicates that the successful tourism promotion by Malaysia in 1990 did appear to have attracted the Japanese visitors away from other economies in the Southeast Asian region. It is noteworthy that the positive impact of $D 90$ is much more significant for Japanese visitors than U.S. visitors. There are two possible reasons for this. First, most Japanese visitors came to the region for sightseeing and with packaged group tours; most U.S. visitors came to the region for business and visiting relatives, and their patterns of travel

19. One possible reason for this result is that Japanese tourists visit both countries in the same trip. 
are individual. Second, the packaged group tours are operated by travel agencies, which generally have more information about promotional campaigns than individual tourists do. Because the Visit Malaysia Year campaign in 1990 aimed chiefly at pleasure-oriented visitors, it should not be surprising to find that it had more effect on the Japanese visitors than on the U.S. visitors.

\subsection{Summary and Conclusions}

In response to the continuing growth of national income in most countries, the substantial decline in the real costs of transportation, the liberalization of cross-border movements, and the increasing propensity to travel abroad, most economies in the Southeast Asian region devoted themselves to international tourism and experienced tremendous growth in terms of foreign visitors during the period of 1973 to 1994. Although the Southeast Asian region's share of the total world tourists had been steadily growing, and all economies in the region had a growing or fairly stable share of the world market, some economies had been continuously losing ground, and some other economies had been continuously gaining ground or had experienced ups and downs in the market for international tourism vis-à-vis the neighboring Southeast Asian economies in the past two decades. The main purpose of this paper is, therefore, to examine and identify the factors determining the relative competitiveness of each economy's international tourism industry among a group of rivals consisting of Taiwan, Hong Kong, Singapore, Malaysia, Indonesia, the Philippines, and Thailand.

Based on a two-stage budgeting decision, a theoretical model has been developed. With the assumption of homotheticity in preferences, it is derived that the change in a destination's share of the international tourism budget of a given origin depends on changes in relative prices among alternative destinations and factors affecting preferences. Using each economy's share of the total visitors from an origin to all the destinations as the proxy for the dependent variable, and with the CPI in each destination as the proxy for the price of tourism services, an empirical analysis by 3SLS has been performed. Two origins (the United States and Japan) and seven destinations (Taiwan, Hong Kong, and the ASEAN Five) are considered for four different samples. The major findings are, first, that the relative price effect depends critically on the purposes of visit and the patterns of travel. U.S. visitors are not sensitive to price fluctuations in Taiwan and Singapore due to the fact that the majority of them come to the two economies for business or to visit relatives. Japanese visitors are not sensitive to the relative price variations in the Southeast Asian destinations, except Singapore, because the majority of them come to these destinations with packaged group tours, which are run by the better-bargaining-power travel agencies. Second, the exchange rate effect depends on whether the tourism expendi- 
tures in the destinations are priced in local currencies or the currency of the origin country. International tourists are not sensitive to the variations in exchange rates if a considerable part of the travel expenses in the destinations are priced in the currencies in their origin countries. Third, supplyside factors could indeed have decisive influences on the market share. However, their effects appear to be origin- and destination-dependent. China's open-door policy stands out as the single most important factor responsible for the loss of Taiwan's market share and a major factor in the gain of Hong Kong's market share in the United States. It seems, however, to have a less significant impact on Japanese visitors to Taiwan and Hong Kong. The promotional campaign of Malaysia in 1990 did have a significant impact on the Malaysian competitiveness in the United States and Japan. Social-political disorder in the Philippines had a negative impact on U.S. visitors, and it also led to the gain of Hong Kong's and the loss of Singapore's and Indonesia's relative competitiveness in the United States. In contrast, the social-political disorder in the Philippines has not had any significant impact on Japanese visitors to the Philippines, but it did lead to the gain of Taiwan's and Hong Kong's, and the loss of Singapore's, relative competitiveness in the Japan market.

The empirical results in this paper yield two important lessons. First, different promotional strategies may be produced for different countries of origin. The relative price effect depends on the purposes of the visit and the patterns of travel; the exchange rate effect depends on whether the tourism expenditures in the destinations are priced in local currencies or the currency of the origin country; and the supply-side effects are origin- and destinationdependent. As a consequence, it could be a serious mistake to treat all foreign visitors as homogeneous in designing any policy to attract foreign visitors. In other words, a successful promotional policy for any destination demands an in-depth study of the characteristics of visitors from various origins and the destination itself. Secondly, it is suspected that the perverse price effect and the perverse exchange rate effect obtained in tables 10.2 and 10.3 could be due to the omission of important explanatory variables. Therefore, more data on potential supply-side variables are needed if the determinants of international tourism are to be understood more thoroughly. Only in this way can more meaningful policy implications be obtained.

\section{References}

Artus, J. R. 1972. An econometric analysis of international travel. International Monetary Fund Staff Papers 19 (3): 579-614.

Chu, F. L. 1993. Elasticities of substitution in Pacific Rim tourism. National Taiwan University, Graduate Institute of National Development. Mimeograph. 
Crouch, G. I. 1992. Effects of income and price on international tourism. Annals of Tourism Research 19:643-64.

Crouch, G. I., and R. N. Shaw. 1990. Determinants of international tourist flows: Findings from thirty years of empirical research. In The tourism connection: Linking research and marketing. Proceedings of the Twenty-First Annual Conference of the Travel and Tourism Research Association, 45-60. Salt Lake City, Utah: TTRA.

Deaton, A., and J. Muellbauer. 1980. An almost ideal demand system. American Economic Review 70:312-26.

Eadington, W. R., and M. Redman. 1991. Economics and tourism. Annals of Tourism Research 18:41-56.

Gujarati, D. N. 1988. Basic econometrics, 2nd ed. New York: McGraw-Hill.

Hitchcock, M., V. T. King, and M. J. G. Parnwell. 1993. Tourism in South-East Asia. London: Routledge.

Martin, C. A., and S. F. Witt. 1987. Tourism forecasting models: Choice of appropriate variable to represent tourists' cost of living. Tourism Management 8:223-45.

Moshirian, F. 1993. Determinants of international trade flows in travel and passenger services. Economic Record 69 (206): 239-52.

O'Hagan, J. W., and M. J. Harrison. 1984. Market shares of U.S. tourist expenditures in Europe: An econometric analysis. Applied Economics 16 (6): 9119-31.

Pindyck, R. S., and D. L. Rubinfeld. 1981. Econometric models and economic forecasts, 2nd ed. New York: McGraw-Hill.

Truett, D. B., and L. J. Truett. 1987. The response of tourism to international economic conditions: Greece, Mexico, and Spain. Journal of Developing Areas 21 (2): 177-90.

Tsai, P. L., and K. L. Wang. 1998. Competitiveness of international tourism in Taiwan: U.S. versus Japanese visitors. Applied Economics 30:631-41.

Varian, H. R. 1992. Microeconomic analysis, 3rd ed. New York: W. W. Norton.

White, K. J. 1985. An international travel demand model: U.S. travel to Western Europe. Annuals of Tourism Research 12 (4): 529-45.

World Tourism Organization(WTO). 1999. Yearbook of Tourism Statistics. Madrid, Spain: WTO.

\section{Comment Keiko Ito}

First of all, we should underline the fact that this paper deals with a topic that is not yet very developed in economics literature. In development studies, it is widely recognized that tourism makes a very significant contribution to the acquisition of foreign currencies for developing economies. According to the World Bank's World Development Indicators, the share of travel services in total exports is relatively high in these countries. For example, it was about 10 percent in Indonesia, Thailand, and the Philippines in 1995. Although there are several conceptual difficulties when considering tourism and a lack of appropriate data for empirical analyses, much more attention should be paid to international tourism as a major export industry.

Keiko Ito is a research assistant professor at the International Centre for the Study of East Asian Development in Kitakyushu, Japan. 
Confronting these difficulties, the authors try to estimate the sensitivity of a destination's share of the international tourism budget to changes in relative prices among different destinations. This paper is certainly an original work with respect to the following points:

1. It is probably the first work that simultaneously estimates the tourism demand model for seven Southeast Asian countries and compares the travel patterns of American and Japanese tourists.

2 . The estimated results clearly show that the factors affecting preferences are very different between American and Japanese tourists. In particular, they confirm that social or political events and marketing promotion have significant impacts on tourists' preferences. The results, therefore, provide some relevant policy implications.

3. This study finds that American tourists are relatively price sensitive, whereas Japanese ones are not so sensitive to price variation. In addition, the effect of relative foreign exchange rates variation is different among their destinations.

The last point provides the central theme and focus of analysis in the paper. The authors aim to investigate relative price and exchange rate variations' effects on tourist demand for each destination. However, the estimated sign and significance of the coefficients are very different among the countries of origin and of destination, and it is quite difficult to induce some persuasive interpretations. I summarize the sign and the significance of the relative price and exchange rate variations for the countries in question in table 10C.1. The authors obtain fairly reasonable results for relative price changes for American tourists, who are price sensitive in most of their seven destinations. However, for Indonesia, the coefficient of relative price changes is positive and significant. The authors give two interpretations for this result. The first one is that Indonesia and the Philippines seem to be complements in the U.S. market, and, therefore, it is reasonable to expect a significantly positive relative price change effect. However, I am not quite sure from where this interpretation derives. I think that without more thorough investigation, we cannot determine which country is a substitute for, or a complement of, any particular country. Rather, I agree with the authors' second interpretation, that some important explanatory variables such as transportation costs are missing from the empirical study. As the authors mention, the local government monopolizes the Indonesian airline industry, and the consumer price index (CPI) does not reflect adequately the price for tourists. Although the authors explain that some previous studies did not provide evidence of clear superiority of a tourist price index to the CPI, I still have some questions on using CPI as a proxy for the price index. When the CPI is used, the estimated parameters do not necessarily reflect the true elasticity of demand for travel services with respect to the relative price of travel services. Particularly in developing countries, the price of travel services, which is mostly for foreigners and richer people, might be 
Table 10C.1 Summary of Sign and Significance of Coefficients

\begin{tabular}{|c|c|c|c|c|}
\hline \multirow[b]{3}{*}{ Destination } & \multicolumn{4}{|c|}{ Origin } \\
\hline & \multicolumn{2}{|c|}{ United States } & \multicolumn{2}{|c|}{ Japan } \\
\hline & $\begin{array}{l}\text { Price } \\
\text { Change }\end{array}$ & $\begin{array}{c}\text { Exchange } \\
\text { Rate }\end{array}$ & $\begin{array}{c}\text { Price } \\
\text { Change }\end{array}$ & $\begin{array}{c}\text { Exchange } \\
\text { Rate }\end{array}$ \\
\hline Taiwan & + & + & + & $-^{*}$ \\
\hline Hong Kong & _*** & + & + & + \\
\hline Singapore & - & + & $+*$ & - \\
\hline Malaysia & _* & _*** & - & + \\
\hline Indonesia & $+* * *$ & + & - & + \\
\hline The Philippines & $-* * *$ & $+*$ & + & $-*$ \\
\hline Thailand & - *** & ${ }^{*} *$ & + & $+* *$ \\
\hline
\end{tabular}

Source: Summarized by the discussant using the estimated results of tables 10.2 and 10.3.

***Significant at the 1 percent level.

**Significant at the 5 percent level.

*Significant at the 10 percent level.

different from the CPI. Therefore, I think that it is still worth constructing the tourist price index and investigating its validity.

As for the price sensitivity of Japanese tourists, the authors explain that the Japanese are not price sensitive because the majority of them travel in packaged group tours. This interpretation seems quite reasonable, but I still wish to suggest using the tourist price index. Moreover, careful investigation is further required for the effect of exchange rates. As shown in table 10C.1, the signs of the coefficients are different among the origins and the destinations, and there are no clear rules for the variation of signs. I partially agree with the authors' view that international tourists are not sensitive to the variations in exchange rates if a considerable part of the travel expenses in their destinations are priced in the currency of their own countries. However, for example, airfares, which are a major proportion of travel expenses, usually reflect exchange rate fluctuations.

Therefore, I still expect that the exchange rate variation has a more significant impact on both American and Japanese tourists. Again, the most likely reason for these ambiguous results for the exchange rate variations might be that some other important explanatory variables are missing. To investigate the relative price change effects, one possible alternative is that one could use the exchange rate-adjusted tourist price index instead of using the price index and the exchange rate separately. Moreover, one could use a better proxy for the supply-side factors rather than using the time trend.

So far, I have commented on the price and exchange rate sensitivity. Although there are some setbacks in constructing dependent and independent variables, I should emphasize that the major findings from this study provide some interesting evidence and implications. That is, the travel patterns 
of American and Japanese tourists are very different, and so are the price sensitivities of both. This implies that policy makers of each destination are required to consider the most effective strategy for each origin.

Last but not least, I would like to confirm again this paper's important contributions to the field of empirical analysis of tourism in Southeast Asian countries. Even if there are many limitations, by using considerably longer time series data, this paper represents a pioneering piece of work and raises an important issue that is definitely lacking detailed data of the tourism industry in this region. Further research, incorporating more supply-side and country-specific factors, should be encouraged.

\section{Comment Mahani Zainal-Abidin}

The paper investigates the relative competitiveness of international tourism among a group of seven East Asian economies. The study shows that some destinations did indeed lose their competitiveness, and it highlights some interesting findings, namely:

1. Tourists are not sensitive to relative price variations if their purposes for visiting are business or to visit relatives or if they come in a packaged tour.

2. Tourists are not sensitive to relative variations in exchange rates if most of the tourism expenditures at the place of destination are priced in their home currencies.

3. Qualitative supply-side factors have a decisive influence on a country market share, but they are origin- and destination-dependent.

Tourism trade is an important gross domestic product (GDP) contributor to many developing economies. Many of these countries have offered tourism in their General Agreement on Trade in Services (GATS) liberalization commitment because they feel that they have a comparative advantage in this area. Therefore, it is important that East Asian economies maintain or increase their competitiveness to raise the GDP contribution of this industry in their respective economies. In this regard, this paper has dealt with an important issue of relative competitiveness between countries and the factors that influence the demand for tourism services.

I enjoyed reading the paper because it gives an extensive exposition on the topic of demand for tourism services. My comments follow.

\section{Why Europe is Not Included in the Set of Origins}

The paper (which only considers the United States and Japan) assumes that tourism markets are interchangeable, whereas tourism products are 
homogeneous and substitutable. In reality, tourism markets are segmented and sometimes product specific. For example, tourists from the United States are likely to visit Taiwan, Hong Kong, the Philippines, and Thailand because of historical ties and political links. The Philippines has very close political links with the United States, and Thailand was the military base for the United States during the Indo-Chinese war. On the other hand, European tourists feature significantly in Malaysia, Singapore, and Indonesia, again due to historical links.

Therefore, in evaluating the relative competitiveness in the tourism industry among East Asian countries, it is essential that the universe of the origin be as comprehensive as possible. It is unlikely that Malaysia, for example, develops competitiveness in the U.S. market when most of the time the majority of its tourists are from European countries.

In part, this is due to the nature of tourism, which is such that information and marketability of a destination take a long time to be developed. Furthermore, the tourism market is relatively segmented and product specific: for example, some Association of Southeast Asian Nations (ASEAN) destinations, such as Malaysia, Indonesia, and Thailand, have developed a market niche in eco-tourism and consequently are almost noninterchangeable with other destinations. Similarly, Hong Kong is a getaway to China and attracts tourists when China opens its doors to foreign tourists.

Perhaps in analyzing the issue of relative competitiveness, it is useful to consider the rate of growth in tourist arrivals and tourism contribution in each destination in addition to the present analysis of relative share of tourism expenditure. In this way, we can incorporate arrivals from new markets-for example, Australian tourists are emerging as a significant source of tourism for ASEAN destinations.

\section{Tour Packages and Intragroup Tourism}

The paper acknowledges the importance of packaged or intragroup tourism but decided to limit or exclude their role. In ASEAN, at least, a substantial portion of tourists, particularly from Japan, come in this form. They generally do not make a single destination trip but conduct a tour of ASEAN destinations - starting perhaps with Singapore, followed by Malaysia, and ending up in Thailand. It is important to include this form of tourism if we want to evaluate the relative competitiveness of the various destinations because it constitutes a large part of tourism in these destinations.

\section{Relative Price Variations}

In most of the estimated equations, the price coefficients met the expected signs: namely, a price reduction will increase the demand for tourism. However, there are instances in which the estimates are contrary to expectation; that is, the price coefficient is positive. 
Once again, this is the case of a segmented market where a price increase indicates quality improvement, which has resulted in higher demand for tourism services. Not all increases in tourism services are generated by lower prices. For example, prices in Singapore have been increasing, but tourist arrival has not dropped. Singapore has increased the quality of its services to compensate for higher costs, and now it targets the higher end of the tourist market.

Thus, the paper may wish to reevaluate the competitiveness of such markets to include improvement in quality of services.

\section{Variation of Samples}

The paper gives the variations of samples used in the estimation. It would help the readers if these variations were put in a table for easier reading. The paper should also explain these variations. For example, for the destination of Indonesia, sample 3 deletes the Philippines, Taiwan, and Hong Kong.

\section{Supply-Side Factors}

Relative competitiveness is significantly influenced by supply-side factors. I do agree with the authors that marketing efforts are critical, but they are difficult to incorporate in econometric equations.

In the last two years, marketing has featured very prominently in the drive to attract tourists - Thailand with its hugely successful Amazing Thailand campaign and Singapore with its shopping and art festivals. Perhaps this factor should be included in the estimation of competitiveness in view of its importance.

Another important supply-side factor is the price of airfares and airlines' availability and connections. Each destination has used its national airline as a key channel to attract tourists by offering steep discounts in airfares. As with marketing, this factor is difficult to qualify but worth considering.

\section{Effects of the Crisis}

The East Asian Crisis has caused sharp currency devaluation in most of the destinations. What are the effects of this depreciation on the demand for tourism services and the relative competitiveness of these destinations? For example, it would be very interesting to compare the effects of currency devaluation between Thailand and Malaysia during the Crisis, because the former enjoyed a tourism boom during the crisis, whereas the latter did not when they both experienced a similar level of depreciation.

This brings to attention the question of whether prices or supply-side factors are more important in influencing the demand for tourism services. 
